\title{
Divergência genética de feijão-caupi (Vigna unguiculata) no sul do Tocantins
}

\section{Genetic divergence of cowpea in the south of Tocantins}

\author{
Sérgio Sousa, Taynar Tavares, Hélio Barros, Ildon Nascimento, Vanessa Santos \\ e Rodrigo Fidelis*
}

Departamento da Pós Graduação em Produção Vegetal (UFT), Universidade Federal do Tocantins, Gurupi, Brasil

( ${ }^{\star}$ E-mail:fidelisrr@uft.edu.br)

http://dx.doi.org/10.19084/RCA16069

Recebido/received: 2016.05 .30

Recebido em versão revista/received in revised form: 2016.09.27

Aceite/accepted: 2016.11.07

\begin{abstract}
R E S U M O
Diante do crescente aumento populacional e da importância do feijão-caupi como fonte de alimentação básica de várias populações, existe a necessidade de novos estudos que auxiliem o processo de obtenção de genótipos superiores. Sendo assim, objetivou-se com este trabalho avaliar a divergência genética de vinte e quatro genótipos de feijão-caupi no Estado do Tocantins, visando a indicação das combinações mais promissoras para compor um programa de melhoramento genético para condições de baixo nível tecnológico. O estudo foi conduzido em delineamento de blocos casualisados, com três repetições e 24 tratamentos. Para a divergência genética foram analisados o número de dias até à floração, o número de dias para maturação das vagens, número de vagens por planta, número de grãos por vagem, comprimento das vagens, índice de grãos, peso de cem sementes e produtividade de grãos. A divergência genética foi obtida através da distância generalizada de Mahalanobis e os genótipos agrupados pelos métodos de Tocher e UPGMA. Foram identificadas diferentes combinações que podem gerar populações promissoras para serem utilizadas em programas de melhoramento. As combinações entre os genótipos MNC03-725F-3 com MNC03-737F-5-4 e de MNC03737F-5-11 com MNC03-737F-5-4, são combinações indicadas para a obtenção de populações promissoras quanto à produtividade de grãos em condição de Cerrado no Tocantins.
\end{abstract}

Palavras-chave: Vigna unguiculata, variabilidade, cerrado.

\begin{abstract}
A B S T R A C T
In face of the increasing population growth and the importance of cowpea as a source of basic supply of many populations, there is a need for further studies to assist the development of improved genotypes. Therefore, the objective of this study was to evaluate the genetic divergence of twenty-four cowpea genotypes in the State of Tocantins, aiming the indication of the most promising combinations to integrate a breeding program for low level of technology conditions. The study was conducted in randomized blocks design, with three replications and 24 treatments. For the analysis of genetic divergence, the following parameter were analyzed: flowering date, days to pods maturation, number of pods per plant, number of grains per pod, pods length, grains index, weight of a hundred grains and grains yield. The genetic divergence was obtained by Mahalanobis distance and the genotypes grouped by the Tocher and UPGMA methods. Different combinations that can generate promising populations to be used in breeding programs were identified, namely those between the MNC03-725F-3 and MNC03-737F-5-4 genotypes and between MNC03737F-5-11 and MNC03-737F-5-4 genotypes. They are promising populations concerning productivity of grains in Cerrado conditions in Tocantins.
\end{abstract}

Keywords:Vigna unguiculata, variability, cerrado. 


\section{INTRODUÇÃO}

O crescente aumento da população mundial tem apresentado um grave problema social conduzindo ao desafio de aumentar a produção de alimentos para que não haja fome. Neste contexto, o feijão-caupi (Vigna unguiculata (L. Walp.) como é conhecido no Brasil e em Portugal como feijão-frade é uma importante fonte alimentar para populações menos favorecidas no mundo e nas regiões Norte e Nordeste do Brasil, por ter alto conteúdo energético e ser rico em proteínas, vitaminas e minerais (Kachare et al., 1988; Freire Filho et al., 2005a; Passos et al., 2007; Bertini et al., 2010; Carvalho et al., 2012).

O Brasil figura entre os três maiores produtores de feijão-caupi no mundo com produção estimada de 583,1 mil toneladas no ano agrícola 2013/2014, ficando atrás de Nigéria e Niger que possuem produções superiores a 1,5 milhões de toneladas (Conab, 2014; FAO, 2016). O Estado de Tocantins destaca-se sendo o único produtor de expressão na região Norte na 1. . $^{\text {safra }}$ (sementeiras entre outubro e dezembro), com uma produção de 3,4 mil toneladas no ano agrícola 2014/2015 (Conab, 2016).

No Tocantins, na maioria dos campos agrícolas são utilizados genótipos tradicionais não melhorados ou oriundos de programas de melhoramento conduzidos em outras localidades. Teixeira et al. (2010) afirmam que o uso de genótipos de baixo potencial produtivo é um dos fatores que levam às baixas produtividades observadas nesta cultura. Para Freire Filho et al. (2005b), o feijão-caupi apresenta potencial de produtividades superiores a 6000 kg.ha-1 com a utilização de variedades provenientes da actividade do melhoramento genético.

Diante dessa crescente demanda, existe a necessidade de efetuar novos estudos que auxiliem na obtenção de genótipos melhorados. Para o desenvolvimento de novas cultivares a escolha dos progenitores é uma etapa crucial para obtenção de sucesso (Borém \& Miranda, 2013).

Dentre as técnicas possíveis para a seleção de progenitores, destaca-se a análise de divergência genética. Segundo Cruz et al. (2011), esse tipo de análise permite avaliar os progenitores quanto à divergência entre si com o objetivo de determinar as combinações híbridas que apresentarão maior efeito heterótico e maior heterozigose e consequentemente maior potencial para gerar populações segregantes promissoras para obtenção de cultivares superiores. Estes grupos são formados pela aplicação de métodos de agrupamentos como o de Tocher e o de UPGMA, baseados em medidas de dissimilaridade como a distância de Mahalanobis (Cruz et al., 2011; Kloster et al., 2011; Santos et al., 2011).

Em Tocantins, vários são os estudos de divergência genética realizados com as culturas de soja (Santos et al., 2011), de feijoeiro (Oliveira, 2015) e de milho (Dotto et al., 2010). Porém, estudos deste tipo com a cultura do feijão-caupi são incipientes.

Diante deste contexto, objetivou-se com este trabalho avaliar a divergência genética de vinte e quatro genótipos de feijão-caupi no Estado do Tocantins, visando a indicação das combinações mais promissoras para compor um programa de melhoramento genético para condições de baixo nível tecnológico.

\section{MATERIAL E MÉTODOS}

O estudo foi realizado no ano agrícola 2014/2015, na estação experimental da Universidade Federal do Tocantins, Campus de Gurupi, localizada a latitude de $11^{\circ} 43^{\prime} 45^{\prime \prime} \mathrm{S}$ e longitude de $49^{\circ} 04^{\prime} 07^{\prime \prime} \mathrm{W}$, a $280 \mathrm{~m}$ de altitude. O ensaio foi instalado em solo classificado como Latossolo Vermelho - Amarelo distrófico (Embrapa, 2013). O clima da região é do tipo mesotérmico com chuvas de verão e inverno seco (Köppen, 1948). A sementeira foi realizada no dia 17 de janeiro de 2015.

A preparação do solo foi realizada de forma convencional, com uma aração e duas gradagens. A densidade de sementeira foi realizada visando a obtenção de oito plantas por metro linear.

Antes da sementeira, foram colhidas amostras de solo da camada de $0-20 \mathrm{~cm}$ para a caracterização dos atributos químicos e físicos do mesmo. A análise do solo indicou os valores de $\mathrm{pH}$ em $\mathrm{CaCl}_{2}=5,3$; M.O (\%)= 1,7; P (Mehlich) $=10,4 \mathrm{mg}$ $\mathrm{dm}^{-3} ; \mathrm{K}=71 \mathrm{mg} \mathrm{dm}^{-3} ; \mathrm{Ca}+\mathrm{Mg}=2,8 \mathrm{cmol}_{\mathrm{c}} \mathrm{dm}^{-3} ; \mathrm{H}+\mathrm{Al}$ $=2,2 \mathrm{cmol}_{\mathrm{c}} \mathrm{dm}^{-3} ; \mathrm{Al}=0,0 \mathrm{cmol}_{\mathrm{c}} \mathrm{dm}^{-3} ; \mathrm{SB}=2,98 \mathrm{cmol}_{\mathrm{c}}$ 
$\mathrm{dm}^{-3} ; \mathrm{V}=58 \% ; 715 \mathrm{~g} \mathrm{~kg}^{-1}$ de areia; $50 \mathrm{~g} \mathrm{~kg}^{-1}$ de silte e $235 \mathrm{~g} \mathrm{~kg}^{-1}$ de argila.

A adubação de fundo foi determinada com base nos resultados da análise do solo e levando em consideração as recomendações para a cultura do feijão-caupi (Melo et al., 2005). Foram aplicados no sulco $100 \mathrm{~kg} \mathrm{ha}^{-1}$ de adubo formulado $5-25-15$ (NPK). Na adubação de cobertura aos 25 dias após a emergência (DAE) foram aplicados $15 \mathrm{~kg} \mathrm{ha}^{-1}$ de $\mathrm{N}$ e $5 \mathrm{~kg} \mathrm{ha}^{-1}$ de $\mathrm{K}_{2} \mathrm{O}$ na forma de sulfato de amônio e cloreto de potássio, respectivamente. Todos os procedimentos culturais e fitossanitários foram realizados de acordo com a necessidade e recomendações técnicas da cultura (Freire Filho et al., 2005a).

O estudo foi conduzido em um delineamento experimental de blocos casualizados com três repetições e 24 tratamentos. A unidade experimental foi constituída por quatro linhas de 4,0 m de comprimento, espaçadas de $0,75 \mathrm{~m}$. Como área útil foram utilizadas as duas linhas centrais desprezando-se 0,50 $\mathrm{m}$ das extremidades de cada linha e eliminando as duas linhas laterais, colhendo-se linhas de 3,0 m de comprimento, numa área de $4,5 \mathrm{~m}^{2}$.

Os genótipos utilizados para o estudo de divergência genética foram cedidos pela EMBRAPA MEIO-NORTE. Foram avaliados 24 genótipos (6 cultivares comerciais e 18 linhagens), sendo eles: (1) BRS GUARIBA, (2) BRS ITAIM, (3) BRS-CAUAMÉ, (4) BRS-TUCUMAQUE, (5) MNC03-737F-11, (6) MNC02-675F-4-9, (7) MNC02-683F-1, (8) MNC02-675F-9-2, (9) MNC02-675F-4-10, (10) MNC02-684F-5-6, (11) MNC03-725F-3, (12) MNC03-736F-7, (13) MNC02-676F-3, (14) MNC03-737F-5-4, (15) MNC03-737F-5-9, (16) MNC03737F-5-11, (17) MNC03-737F-5-10, (18) MNC03-736F-2, (19) MNC02-677F-2, (20) MNC02-65F-9-5, (21) BRS VINAGRE, (22) BRANQUINHO, (23) MNC02-676F-1 e (24) MNC02-689F-2-8.

As características avaliadas foram: dias até à floração - dias desde a emergência até que $50 \%$ das plantas apresentem flores; dias para a maturação das vagens- dias contados desdea emergência até o aparecimento de mais de $50 \%$ de vagens maduras na parcela e; número de vagens por planta - obtido pela contagem do número total de vagens por planta de cinco plantas escolhidas aleatoriamente na unidade experimental. Em laboratório foram determinadas as seguintes variáveis: índice de grãos - obtido pela fórmula IG $=[(\mathrm{PGV} / 20) /(\mathrm{PV} / 20)$ x100], sendo PGV referente à peso de grãos de 20 vagens e PV referente ao peso das 20 vagens; número de grãos por vagem- obtido pela contagem do número total de grãos oriundos de 20 vagens escolhidas aleatoriamente e dividindo o resultado pelo número total de vagens; comprimento de vagens - obtido pela medição do comprimento de cada uma das 20 vagens selecionadas aletoriamente e dividindo o total pelo número de vagens utilizadas; peso de cem sementes - tomando-se cem sementes da área útil pesando e corrigindo a humidade para $13 \%$ e; produtividade de grãos - pesagem dos grãos da área útil em $\mathrm{kg} \mathrm{ha}^{-1} \mathrm{com}$ correção da humidade para $13 \%$.

Os dados experimentais foram submetidos à análise de variância, com aplicação do teste F. Para as comparações entre as médias das cultivares utilizou-se o teste Scott-Knott (Scott \& Knott, 1974), ao nível de 5\% de probabilidade. Para o agrupamento das cultivares utilizou-se o método de otimização de Tocher e o método Hierárquico de agrupamento médio entre grupos (UPGMA), utilizando-se a distância de Mahalanobis (D2). A contribuição dos caracteres foi quantificada segundo a metodologia de Singh (1981). As análises foram realizadas com a utilização do aplicativo computacional GENES (Cruz, 2008).

\section{RESULTADOS E DISCUSSÃO}

O Quadro 1 apresenta a análise de variância para as características avaliadas. Para as características dias até à floração, dias para a maturação das vagens, índice de grãos, número de grãos por vagem, número de vagens por plantas, peso de cem sementes e produtividade de grãos, observou-se efeito significativo entre os genótipos pelo teste $\mathrm{F}(\mathrm{p} \leq 0,05)$. Porém, para a característica comprimento de vagens não foi observado efeito significativo. A significância observada é indicativo de variabilidade entre os genótipos, o que de acordo com Santos et al. (2012) e Almeida et al. (2011) maximiza a possibilidade de sucesso num programa de melhoramento genético com a utilização destes genótipos. 
Quadro 1 - Análise de variância para as características dias até à floração(DF), dias para a maturação das vagens (DMV), índice de grãos (IG), número de grãos por vagem (NGV), número de vagens por planta (NVP), comprimento de vagens (CVA), pesodecem sementes(PCS)e produtividade de grãos (PG) de vinte e quatro genótipos de feijão-caupi. Ensaio realizado no ano agrícola 2014/2015 no Campus de Gurupi, Universidade Federal de Tocantins.Gurupi, Tocantins

\begin{tabular}{lccccccccc}
\hline \multirow{2}{*}{$\begin{array}{l}\text { Fontes de } \\
\text { Variação }\end{array}$} & GL & DF & DMV & IG & NGV & NVP & CVA & PCS & PG \\
\hline Genótipos & 23 & $3,34^{* *}$ & $7,26^{* *}$ & $9,40^{* *}$ & $3,56^{* *}$ & $10,90^{*}$ & $1,24^{\text {ns }}$ & $3,06^{*}$ & $80963,40^{* *}$ \\
Blocos & 2 & 2,79 & 1,55 & 8,50 & 1,32 & 10,77 & 1,43 & 2,77 & 7850,36 \\
Resíduo & 46 & 1,37 & 2,25 & 4,09 & 1,31 & 5,36 & 0,73 & 1,70 & 14607,47 \\
\hline Média & & 38,58 & 65,55 & 76,53 & 12,29 & 9,70 & 17,73 & 15,99 & 588,90 \\
CV(\%) & & 3,04 & 2,29 & 2,64 & 9,32 & 23,87 & 4,83 & 8,17 & 20,52 \\
\hline
\end{tabular}

GL (Graus de liberdade); ns não significativo; ** significativo para $p \leq 0,01$; * Significativo para $p \leq 0,05$ pelo teste $F$.

Os coeficientes de variação (CV) variaram de 2,29\% para a característica de dias para a maturação das vagens até $23,87 \%$ para o número de vagens por planta (Quadro 1). Os maiores coeficientes de variação observados foram para as características produtividade de grãos $(20,52 \%)$ e número de vagens por planta (23,87\%). Bertiniet al. (2009) avaliando a divergência genética de acessos de feijão-caupi observaram elevados coeficientes de variação para o número de vagens por planta $(35,92 \%)$ e a produção em gramas $(38,91 \%)$.

Em estudos de avaliação de variabilidade entre caracteres agronômicos de linhagens de feijão-caupi, Lopes et al. (2001) também observaram elevado coeficiente de variação para a produtividade de grãos (33,56\%).

No Quadro 2 são apresentadas as médias de cada genótipo para cada uma das oito características avaliadas. Para a característica dias até a floração, foram formados dois grupos estatísticos, sendo o grupo de maiores médias composto por oito genótipos, com médias variando de 39,0 (MNC02-675F-4-10 e MNC02-683F-1) a 40,66 (MNC02-677F-2 e MNC02-65F-9-5). Já o grupo que entrou em floração mais cedo, é composto pelos 16 genótipos restantes, com dias até à floração compreendidos entre 37,33 e 38,66 . A variação observada para a característica dias até à floração foi de 37,33 a 40,66 dias. Santos (2014) avaliando três cultivares de feijão-caupi submetidas a diferentes densidades em condições de Cerrado, observou variação de 43,25 a 49 dias para a floração na densidade de 8 plantas por metro linear, mesma densidade utilizada no presente estudo.
O período para maturação das vagens dos genótipos avaliados variou de 64,0 a 68 dias após a emergência. Assim como ocorreu na característica dias até à floração, os genótipos foram agrupados em dois grupos de acordo com os dias necessários para atingir a maturação das vagens. O grupo formado pelos genótipos que apresentaram maiores médias de dias transcorridos da emergência até a maturação das vagens foi constituído por oito genótipos, com ciclos entre 66,66 a 68. Já os genótipos que alcançaram mais rápido a maturação de vagens, obtiveram ciclos de 64,0 a 65,33 . Nota-se que até mesmo os genótipos que tiveram um ciclo mais longo, não atingiram 70 DAE. De acordo com Freire Filho et al. (2005b), os genótipos em estudo são classificados como precoces.

Considerando que o feijão-caupi no Tocantins pode ser semeado na $1 .^{\text {a }}$ safra (sementeiras entre os meses de outubro e janeiro) que também é conhecida como safra das "águas", principalmente do meio para o final do período chuvoso, todos os genótipos apresentam potencial para serem utilizados em plantios nesta época na região de Cerrrado do Tocantins. Nessa época de sementeira pode haver uma maior concentração de chuvas na fase inicial da cultura, os genótipos precoces podem levar vantagem em relação aos de ciclo normal, minimizando os riscos de efeitos prejudiciais de altas temperaturas na floração e chuvas na colheita (Vale et al., 2015).

Para o índice de grãos, observou-se a formação de um único grupo, onde as médias variaram de 71,91\% para o genótipo BRS-TUCUMAQUE até 80,11\% para MNC02-675F-4-10 (Quadro 2). Esta variação 
Quadro 2 - Médias de dias até à floração(DF), dias para maturação das vagens (DMV), índice de grãos (IG), número de grãos por vagem (NGV), número de vagens por planta (NVP), comprimento de vagens (CVA), pesode cem sementes(PCS) e produtividade de grãos (PG) de 24 genótipos de feijão caupi.Ensaio realizado no ano agrícola 2014/2015 no Campus de Gurupi, Universidade Federal de Tocantins.Gurupi, Tocantins

\begin{tabular}{|c|c|c|c|c|c|c|c|c|}
\hline \multirow{2}{*}{ Genótipos } & DF & DMV & IG & NGV & NVP & CVA & PCS & PG \\
\hline & $\left(\mathrm{DAE}^{1}\right)$ & $(\%)$ & (un) & $(\mathrm{cm})$ & (g) & $\left(\right.$ kg ha $\left.^{-1}\right)$ & & \\
\hline 11 & $37,33 \mathrm{~b}$ & $64,00 \mathrm{~b}$ & $77,10 \mathrm{a}$ & $11,98 \mathrm{~b}$ & $9,60 \mathrm{a}$ & $17,80 \mathrm{a}$ & $16,67 \mathrm{a}$ & 971,99 a \\
\hline 16 & $37,33 \mathrm{~b}$ & $64,00 \mathrm{~b}$ & 78,91 a & $12,56 \mathrm{a}$ & $10,20 \mathrm{a}$ & 18,13 a & $16,42 \mathrm{a}$ & 958,96 a \\
\hline 13 & $37,66 \mathrm{~b}$ & $64,00 \mathrm{~b}$ & 75,59 a & $11,58 \mathrm{~b}$ & $14,00 \mathrm{a}$ & $17,51 \mathrm{a}$ & $16,75 \mathrm{a}$ & $781,03 \mathrm{~b}$ \\
\hline 14 & $38,00 \mathrm{~b}$ & $66,66 \mathrm{a}$ & 76,03 a & $10,38 \mathrm{~b}$ & $10,00 \mathrm{a}$ & $16,78 \mathrm{a}$ & 14,31 a & $718,52 \mathrm{~b}$ \\
\hline 8 & $38,00 \mathrm{~b}$ & $64,00 \mathrm{~b}$ & $74,76 \mathrm{a}$ & $12,33 \mathrm{~b}$ & $11,46 \mathrm{a}$ & $17,83 \mathrm{a}$ & $15,04 \mathrm{a}$ & $681,06 \mathrm{~b}$ \\
\hline 12 & $38,33 \mathrm{~b}$ & $65,33 \mathrm{~b}$ & 77,67 a & $11,78 \mathrm{~b}$ & $13,66 \mathrm{a}$ & 17,08 a & 15,68 a & $671,31 \mathrm{~b}$ \\
\hline 9 & $39,00 \mathrm{a}$ & $64,00 \mathrm{~b}$ & 80,11 a & 13,18 a & $9,93 \mathrm{a}$ & $17,38 \mathrm{a}$ & $17,12 \mathrm{a}$ & $663,32 \mathrm{~b}$ \\
\hline 7 & $39,00 \mathrm{a}$ & $66,66 \mathrm{a}$ & 77,02 a & $12,65 \mathrm{a}$ & $9,40 \mathrm{a}$ & $17,84 \mathrm{a}$ & $14,70 \mathrm{a}$ & $654,94 \mathrm{~b}$ \\
\hline 3 & $37,33 \mathrm{~b}$ & $64,00 \mathrm{~b}$ & 79,56 a & $11,70 \mathrm{~b}$ & $11,80 \mathrm{a}$ & 17,39 a & $15,79 a$ & $625,74 \mathrm{~b}$ \\
\hline 5 & $37,66 \mathrm{~b}$ & $65,33 \mathrm{~b}$ & 76,67 a & $12,08 \mathrm{~b}$ & 11,73 a & $17,55 \mathrm{a}$ & $16,05 \mathrm{a}$ & $609,66 \mathrm{~b}$ \\
\hline 1 & $39,33 \mathrm{a}$ & $68,00 \mathrm{a}$ & 74,83 a & $11,60 \mathrm{~b}$ & $9,06 \mathrm{a}$ & 17,97 a & 15,99 a & $606,66 \mathrm{~b}$ \\
\hline 23 & 39,33 a & $64,00 \mathrm{~b}$ & $76,69 \mathrm{a}$ & $13,90 \mathrm{a}$ & $5,93 \mathrm{a}$ & $19,23 \mathrm{a}$ & 17,18 a & $594,58 \mathrm{~b}$ \\
\hline 4 & $38,33 \mathrm{~b}$ & $64,00 \mathrm{~b}$ & 71,91 a & $12,95 \mathrm{a}$ & $10,80 \mathrm{a}$ & $18,55 \mathrm{a}$ & $17,54 \mathrm{a}$ & $589,38 \mathrm{~b}$ \\
\hline 24 & $40,33 \mathrm{a}$ & $64,00 \mathrm{~b}$ & $75,46 \mathrm{a}$ & $14,56 \mathrm{a}$ & $8,46 \mathrm{a}$ & $17,97 \mathrm{a}$ & $15,52 \mathrm{a}$ & $573,30 \mathrm{~b}$ \\
\hline 22 & $38,00 \mathrm{~b}$ & $68,00 \mathrm{a}$ & 75,94 a & $11,33 \mathrm{~b}$ & $6,93 \mathrm{a}$ & 18,61 a & $17,50 \mathrm{a}$ & $571,63 \mathrm{~b}$ \\
\hline 15 & $38,33 \mathrm{~b}$ & $66,66 \mathrm{a}$ & 79,27 a & $11,63 \mathrm{~b}$ & $9,13 \mathrm{a}$ & $16,90 \mathrm{a}$ & $15,86 \mathrm{a}$ & $549,91 \mathrm{c}$ \\
\hline 19 & $40,66 \mathrm{a}$ & $65,33 \mathrm{~b}$ & $76,79 \mathrm{a}$ & $12,80 \mathrm{a}$ & $8,73 \mathrm{a}$ & $18,02 \mathrm{a}$ & $16,37 \mathrm{a}$ & $462,46 \mathrm{c}$ \\
\hline 2 & $38,33 \mathrm{~b}$ & $65,33 \mathrm{~b}$ & $75,18 \mathrm{a}$ & $12,90 \mathrm{a}$ & $9,66 \mathrm{a}$ & $18,83 \mathrm{a}$ & $16,45 \mathrm{a}$ & $452,95 \mathrm{c}$ \\
\hline 17 & $38,33 \mathrm{~b}$ & $68,00 \mathrm{a}$ & $77,31 \mathrm{a}$ & $11,30 \mathrm{~b}$ & $9,13 \mathrm{a}$ & $16,97 \mathrm{a}$ & $16,22 \mathrm{a}$ & $437,42 \mathrm{c}$ \\
\hline 10 & $38,66 \mathrm{~b}$ & $68,00 \mathrm{a}$ & $75,42 \mathrm{a}$ & $10,21 \mathrm{~b}$ & $7,73 \mathrm{a}$ & $16,70 \mathrm{a}$ & $16,28 \mathrm{a}$ & $415,83 \mathrm{c}$ \\
\hline 20 & $40,66 \mathrm{a}$ & $65,33 \mathrm{~b}$ & $76,00 \mathrm{a}$ & $12,51 \mathrm{a}$ & $10,46 \mathrm{a}$ & 17,36 a & $16,42 \mathrm{a}$ & $409,16 \mathrm{c}$ \\
\hline 18 & $38,33 \mathrm{~b}$ & $65,33 \mathrm{~b}$ & $76,87 \mathrm{a}$ & $14,33 \mathrm{a}$ & $9,06 \mathrm{a}$ & 18,05 a & $13,86 \mathrm{a}$ & $393,08 \mathrm{c}$ \\
\hline 6 & $37,33 \mathrm{~b}$ & $65,33 \mathrm{~b}$ & $76,01 \mathrm{a}$ & $11,65 \mathrm{~b}$ & $8,06 \mathrm{a}$ & $17,62 \mathrm{a}$ & $16,02 \mathrm{a}$ & $383,83 \mathrm{c}$ \\
\hline 21 & $40,33 \mathrm{a}$ & $68,00 \mathrm{a}$ & $75,76 \mathrm{a}$ & $13,21 \mathrm{a}$ & $7,93 \mathrm{a}$ & $17,56 \mathrm{a}$ & $14,02 \mathrm{a}$ & $356,85 \mathrm{c}$ \\
\hline
\end{tabular}

Médias seguidas de mesma letra minúscula na coluna pertencem ao mesmo grupo estatístico pelo teste Scott-Knott ao nível de $5 \%$ de probabilidade. ${ }^{1} \mathrm{DAE}=$ dias após a emergência. (1) BRS GUARIBA; (2) BRS ITAIM; (3) BRS-CAUAMÉ; (4) BRS-TUCUMAQUE; (5) MNC03-737F-11; (6) MNC02-675F-4-9; (7) MNC02-683F-1; (8) MNC02-675F-9-2; (9) MNC02-675F-4-10; (10) MNC02-684F-5-6; (11) MNC03-725F-3; (12) MNC03-736F-7; (13) MNC02-676F-3; (14) MNCO3-737F-5-4; (15) MNC03737F-5-9; (16) MNC03737F-5-11; (17) MNC03-737F-5-10; (18) MNC03-736F-2; (19) MNC02-677F-2; (20) MNC02-65F-9-5; (21) BRS VINAGRE; (22) BRANQUINHO; (23) MNC02-676F-1; (24) MNC02-689F-2-8.

observada é superior à encontrada por Santos et al. (2014) em estudos deavaliação de genótipos de feijão-caupi cultivados em écotono Cerrado/ Pantanal, onde os índices de grãos variaram de 63,3 a 75,1\%. Estes valores altos de índices de grãos são indicativos de eficiência destes genótipos no redirecionamento dos fotoassimilados para os grãos, o que possivelmente poderá ter reflexo no incremento de produtividade.

Com relação ao número de grãos por vagem, os genótipos foram agrupados em dois grupos (Quadro 2). O grupo das maiores médias de número de grãos por vagem foi constituído por 11 genótipos, onde as médias variaram de 12,51 (MNC02-65F-9-5) a 14,56 (MNC02-689F-2-8) grãos por vagem. Os demais genótipos estudados apresentam médias de grãos por vagem inferiores a 12,51. Santos (2014) em condições de Cerrado observou variação de 12,95 a 14,95 grãos por vagem.

Para o número de vagens por planta, houve a formação de apenas um grupo, com valores variando de 5,93 (MNC02-676F-1) a 14,00 (MNC02-676F-3) vagens por planta (Quadro 2). Todos os genótipos apresentaram número de vagens por 
planta inferior a 20 unidades, o que de acordo com Oliveira et al. (2002) estaria abaixo do padrão da espécie que seria de valores superiores a 20 unidades.

Quanto à característica de comprimento de vagens (CVA), os genótipos foram organizados em um único grupo, não sendo observadas desta forma, diferenças estatísticas. As médias de comprimento encontradas variaram de 16,70 (MNC02-684F-5-6) a 19,23 cm (MNC02-676F-1) (Quadro 2). Os valores encontrados estão abaixo do padrão comercial desejado que é de comprimento de vagem superior a $20 \mathrm{~cm}$ (Silva \& Neves, 2011; Oliveira et al., 2015). Observa-se que os genótipos que obtiveram os maiores valores de número de grãos por vagem também apresentaram altos valores de comprimento de vagens, embora para o comprimento de vagens os genótipos tenham sido organizados em um único grupo. Santos (2014) afirma que um maior comprimento de vagem pode favorecer ao maior número de locus e consequentemente maior quantidade de grãos por vagem.

Para a característica de peso de cem sementes, os genótipos também foram organizados em um único grupo (Quadro 2). Os pesos variaram de 13,86 (MNC03-736F-2) a 17,54 gramas (BRS-TUCUMAQUE). De acordo com Silva \& Neves (2011) e Oliveira et al. (2015), existe uma preferência por grãos com peso de 100 grãos em torno de $18 \mathrm{~g}$.

Em relação à produtividade de grãos, diferentemente de DF, DMV e NGV, os genótipos foram organizados em três grupos. As maiores produtividades foram obtidas no grupo constituído por MNC03-725F-3 e MNC03737F-5-11, que obtiveram respectivamente 971,99 e 958,96 $\mathrm{kg} \mathrm{ha}^{-1}$. Estas produtividades estão abaixo dos maiores valores encontrados por Benvindo et al. (2010) em condições de sequeiro, onde as maiores produtividades foram superiores a $1002,7 \mathrm{~kg} \mathrm{ha}^{-1}$ e também são inferiores às encontradas por Teixeira et al. (2010) que obtiveram produtividades superiores a $2.000 \mathrm{~kg} \mathrm{ha}^{-1}$ em condições de Cerrado no sudeste goiano. O grupo intermediário foi constituído por 13 genótipos, com produtividades de grãos que variaram de 781,03 (MNC02-676F-3) a 571,63 $\mathrm{kg} \mathrm{ha}^{-1}$ (BRANQUINHO). O grupo com menores rendimentos foi constituído pelos demais genótipos que apresentaram produtividades de grãos inferiores a
$550 \mathrm{~kg} \mathrm{ha}^{-1}$. A média geral de produtividade foi de $588,90 \mathrm{~kg}$ ha $^{-1}$ (Quadro 2). Em avaliação de 20 genótipos de feijão-caupi em condições de sequeiro Benvindo et al. (2010), obtiveram média geral de $851,59 \mathrm{~kg} \mathrm{ha}^{-1}$. Teixeira et al. (2010) avaliando oito genótipos em Cerrado goiano obtiveram média geral de $1.307 \mathrm{~kg} \mathrm{ha}^{-1}$.

Os genótipos MNC03-725F-3 e MNC03737F-5-11 destacaram-se por apresentarem produtividades acima de $900 \mathrm{~kg} \mathrm{ha}^{-1}$. Estes rendimentos são superiores à média nacional $\left(383 \mathrm{~kg} \mathrm{ha}^{-1}\right)$ e do Estado deTocantins $\left(657 \mathrm{~kg} \mathrm{ha}^{-1}\right)$ considerando as estimativas da 1. a safra do ano agrícola 2015/2016 (Conab, 2016). Sendo assim, estes genótipos podem ser promissores para o cultivo em condições de baixa tecnologia de Cerrado no Tocantins. Estas maiores produtividades obtidas pelos genótipos $\mathrm{MNC03-}$ -725F-3 e MNC03737F-5-11 podem ser explicados pelos altos valores de número de grãos por vagem, comprimento de vagens, índice de grãos e peso de cem sementes. Segundo Lopes et al. (2001) o número de grãos por vagem, comprimento de vagens e peso de cem sementes possuem forte relação com a produtividade.

Embora tenham se destacado com as maiores produtividades (Quadro 2), não se recomenda o cruzamento dos genótipos MNC03-725F-3 e MNC03737F-5-11 entre si, pois ambos são considerados similares, compondo os mesmos grupos, tanto pelo método de agrupamento de Tocher (Quadro 3), como pelo método de UPGMA (Figura 1). Esta similaridade também é comprovada pelo teste Scott-Knott, onde estes dois genótipos só compuseram grupos diferentes para a característica de número de grãos por vagem (Quadro 2).

No Quadro 4 são apresentadas as medidas de dissimilaridade genética dos genótipos avaliados, estimadas a partir da distância de Mahalanobis. Observa-se que a amplitude entre os valores encontrados é pequena, sendo o menor valor de 1,59 entre os genótipos MNC02-677F-2 (19) e MNC02-65F-9-5 (20), e o maior valor de 41,36 entre BRANQUINHO (22) e MNC02-689F-2-8 (24).

As combinações mais divergentes com distâncias superiores a $\mathrm{D}^{2}=35,00$ foram entre os genótipos: (11) MNC03-725F-3 e (18) MNC03-736F-2, (18) MNC03-736F-2 e (22) BRANQUINHO, (11) MNC03-725F-3 
Quadro 3 - Representação do agrupamento pelo método de Otimização de Tocher com base na distância generalizada de Mahalanobis entre os 24 genótipos de feijão-caupi. Ensaio realizado no ano agrícola 2014/2015 no Campus de Gurupi, Universidade Federal de Tocantins.Gurupi, Tocantins

\begin{tabular}{|c|c|c|}
\hline Grupo & Genótipos & $\%$ \\
\hline I & $\begin{array}{l}\text { MNC02-677F-2 (19), MNC02-65F-9-5 (20), BRS ITAIM (2), MNC02-676F-1 } \\
\text { (23), MNC03-737F-11 (5), MNC02-675F-9-2 (8) e MNC02-683F-1 (7) }\end{array}$ & 29,17 \\
\hline II & $\begin{array}{c}\mathrm{MNC0}-725 \mathrm{~F}-3(11), \mathrm{MNC0} 3737 \mathrm{~F}-5-11(16), \mathrm{MNCO} 2-676 \mathrm{~F}-3 \text { (13), MNC03- } \\
736 \mathrm{~F}-7 \text { (12) }\end{array}$ & 16,67 \\
\hline III & $\begin{array}{c}\mathrm{MNC03}-737 \mathrm{~F}-5-9(15), \mathrm{MNC03}-737 \mathrm{~F}-5-10(17), \mathrm{MNC02}-684 \mathrm{~F}-5-6(10), \\
\text { MNC02-675F-4-9 (6) }\end{array}$ & 16,67 \\
\hline IV & BRS-CA UAMÉ (3), MNCO2-675F-4-10 (9) & 8,33 \\
\hline $\mathrm{V}$ & BRS GUARIBA (1), MNCO3-737F-5-4 (14) & 8,33 \\
\hline VI & MNC03-736F-2 (18), BRS VINAGRE (21) & 8,33 \\
\hline VII & MNC02-689F-2-8 (24) & 4,17 \\
\hline VIII & BRS-TUCUMAQUE (4) & 4,17 \\
\hline IX & BRANQUINHO (22) & 4,17 \\
\hline
\end{tabular}

Método de agrupamento: Ligação Média Entre Grupo (UPGMA)

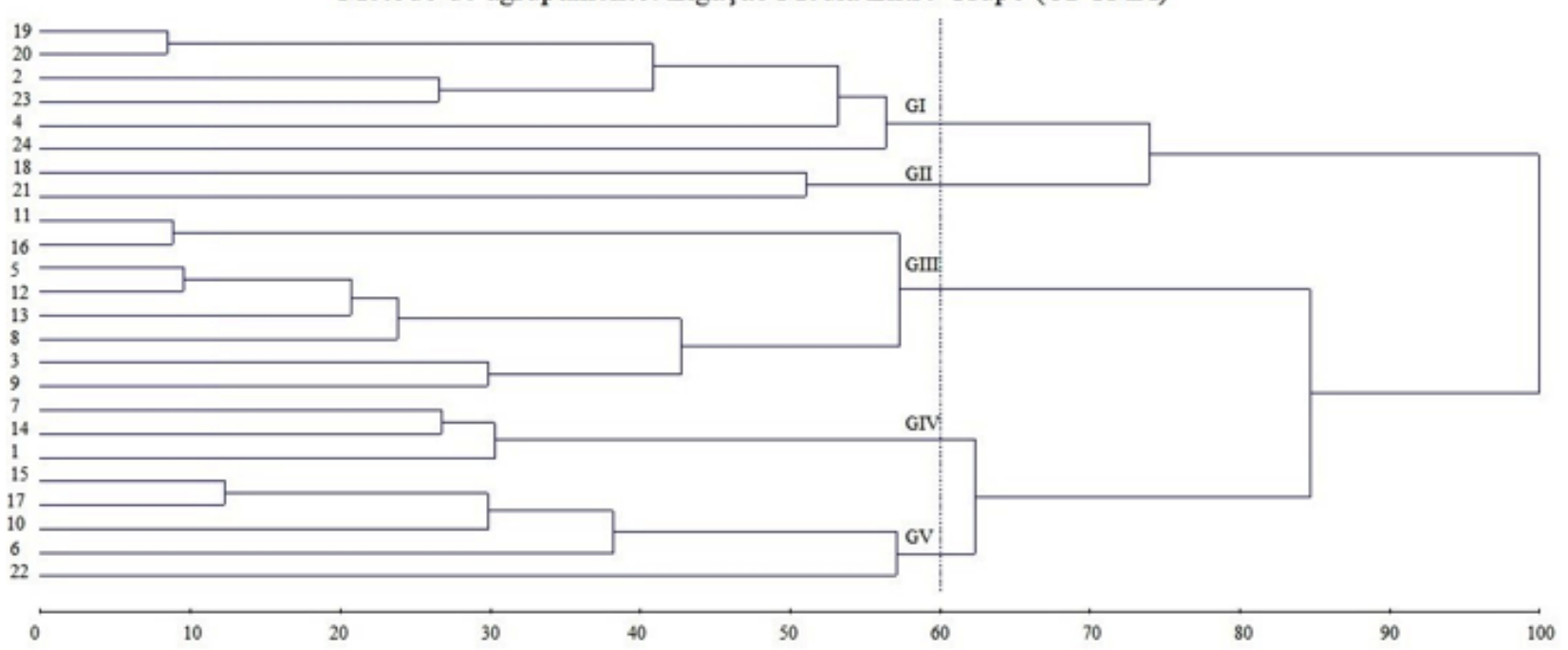

Figura 1 - Dendograma representativo da dissimilaridade genética entre 24 genótipos de feijão-caupi, obtidos pelo método de agrupamento UPGMA, utilizando a distância generalizada de Mahalanobis como medida de dissimilaridade. (1) BRS GUARIBA, (2) BRS ITAIM, (3) BRS-CAUAMÉ, (4) BRS-TUCUMAQUE, (5) MNC03-737F-11, (6) MNC02-675F-4-9, (7) MNC02-683F-1, (8) MNCO2-675F-9-2, (9) MNC02-675F-4-10, (10) MNC02-684F-5-6, (11) MNC03-725F-3, (12) MNC03-736F-7, (13) MNC02-676F-3, (14) MNC03-737F-5-4, (15) MNC03-737F-5-9, (16) MNC03737F-5-11, (17) MNC03737F-5-10, (18) MNC03-736F-2, (19) MNC02-677F-2, (20) MNC02-65F-9-5, (21) BRS VINAGRE, (22) BRANQUINHO, (23) MNC02-676F-1 e (24) MNC02-689F-2-8. Linha pontilhada: corte no dendrograma em aproximadamente $60 \%$ da máxima distância. GI a GV representam os 5 grupos formados. 
Quadro 4 - Dissimilaridade genética entre vinte e quatro genótipos de feijão caupi em relação a oito caracteres, baseado na distância generalizada de Mahalanobis ( $\mathrm{D}^{2} \mathrm{ii}$ ')

\begin{tabular}{|c|c|c|c|c|c|c|c|c|c|c|c|c|c|c|c|c|c|c|c|c|c|c|c|}
\hline C & 2 & 3 & 4 & 5 & 6 & 7 & 8 & 9 & 10 & 11 & 12 & 13 & 14 & 15 & 16 & 17 & 18 & 19 & 20 & 21 & 22 & 23 & 24 \\
\hline 1 & 10,98 & 22,53 & 15,32 & 10,11 & 17,15 & 5,08 & 12,09 & 19,64 & 8,47 & 15,89 & 12,31 & 14,49 & 6,23 & 11,58 & 20,23 & 8,66 & 27,37 & 10,58 & 14,39 & 13,35 & 7,04 & 14,84 & 23,06 \\
\hline 2 & & 11,52 & 7,41 & 4,93 & 5,56 & 8,62 & 7,10 & 10,44 & 15,03 & 20,64 & 10,54 & 12,61 & 17,24 & 10,85 & 20,97 & 10,17 & 10,60 & 5,33 & 8,09 & 13,15 & 13,56 & 4,95 & 14,17 \\
\hline 3 & & & 25,30 & 4,19 & 10,38 & 12,16 & 11,00 & 5,57 & 23,14 & 14,17 & 5,52 & 10,18 & 14,70 & 6,16 & 10,41 & 12,98 & 17,94 & 17,80 & 21,20 & 29,27 & 21,77 & 17,11 & 29,37 \\
\hline 4 & & & & 11,60 & 18,47 & 16,17 & 7,37 & 18,39 & 25,41 & 21,18 & 16,21 & 10,92 & 24,11 & 25,60 & 26,26 & 23,76 & 22,17 & 11,04 & 10,93 & 22,19 & 25,09 & 10,32 & 11,43 \\
\hline 5 & & & & & 7,98 & 4,76 & 3,81 & 5,34 & 14,71 & 10,30 & 1,78 & 4,37 & 8,30 & 5,04 & 10,04 & 7,57 & 13,18 & 9,94 & 11,64 & 17,13 & 14,65 & 11,38 & 17,68 \\
\hline 6 & & & & & & 14,27 & 14,52 & 12,71 & 8,83 & 26,42 & 15,70 & 21,03 & 17,22 & 6,70 & 27,38 & 5,87 & 12,97 & 11,06 & 13,36 & 16,40 & 14,06 & 11,52 & 24,09 \\
\hline 7 & & & & & & & 5,29 & 10,06 & 14,98 & 11,37 & 5,52 & 10,59 & 5,00 & 7,04 & 11,83 & 9,54 & 13,38 & 8,70 & 12,57 & 9,71 & 14,66 & 11,24 & 14,23 \\
\hline 8 & & & & & & & & 10,36 & 22,91 & 10,31 & 4,99 & 4,52 & 9,98 & 14,10 & 11,88 & 17,61 & 13,18 & 10,60 & 12,22 & 17,28 & 23,41 & 10,91 & 10,89 \\
\hline 9 & & & & & & & & & 22,43 & 14,29 & 6,33 & 10,92 & 18,22 & 6,79 & 12,18 & 13,16 & 14,91 & 9,42 & 11,69 & 21,48 & 23,58 & 9,73 & 15,39 \\
\hline 10 & & & & & & & & & & 29,36 & 20,19 & 26,39 & 11,74 & 8,15 & 34,65 & 2,99 & 29,54 & 13,90 & 15,71 & 15,65 & 8,40 & 21,29 & 33,12 \\
\hline 11 & & & & & & & & & & & 10,68 & 6,57 & 9,95 & 16,98 & 1,64 & 23,92 & 36,31 & 25,65 & 31,88 & 39,06 & 19,21 & 18,41 & 31,04 \\
\hline 12 & & & & & & & & & & & & 3,35 & 8,56 & 7,50 & 9,71 & 11,71 & 17,75 & 12,79 & 13,60 & 20,41 & 21,21 & 17,68 & 19,88 \\
\hline 13 & & & & & & & & & & & & & 11,81 & 15,78 & 7,86 & 19,81 & 27,40 & 17,76 & 18,94 & 31,27 & 22,58 & 18,15 & 23,07 \\
\hline 14 & & & & & & & & & & & & & & 8,49 & 13,13 & 10,30 & 27,53 & 18,55 & 22,36 & 20,14 & 13,34 & 22,22 & 29,30 \\
\hline 15 & & & & & & & & & & & & & & & 16,19 & 2,30 & 16,98 & 11,70 & 14,82 & 15,84 & 11,74 & 15,38 & 25,97 \\
\hline 16 & & & & & & & & & & & & & & & & 25,28 & 33,66 & 27,38 & 34,49 & 41,13 & 22,13 & 19,39 & 33,42 \\
\hline 17 & & & & & & & & & & & & & & & & & 19,78 & 11,52 & 13,42 & 13,08 & 8,44 & 17,70 & 28,41 \\
\hline 18 & & & & & & & & & & & & & & & & & & 13,10 & 13,74 & 9,53 & 37,58 & 15,78 & 10,72 \\
\hline 19 & & & & & & & & & & & & & & & & & & & 1,59 & 7,52 & 19,45 & 5,68 & 8,00 \\
\hline 20 & & & & & & & & & & & & & & & & & & & & 7,84 & 26,68 & 11,38 & 7,60 \\
\hline 21 & & & & & & & & & & & & & & & & & & & & & 27,59 & 17,67 & 11,15 \\
\hline 22 & & & & & & & & & & & & & & & & & & & & & & 16,76 & 41,36 \\
\hline 23 & & & & & & & & & & & & & & & & & & & & & & & 11,43 \\
\hline
\end{tabular}

C = Genótipos: (1) BRS GUARIBA, (2) BRS ITAIM, (3) BRS-CAUAMÉ, (4) BRS-TUCUMAQUE, (5) MNC03-737F-11, (6) MNC02-675F-4-9, (7) MNC02-683F-1, (8) MNC02675F-9-2, (9) MNC02-675F-4-10, (10) MNC02-684F-5-6, (11) MNC03-725F-3, (12) MNC03-736F-7, (13) MNC02-676F-3, (14) MNC03-737F-5-4, (15) MNC03-737F-5-9, (16) MNC03737F-5-11, (17) MNC03-737F-5-10, (18) MNC03-736F-2, (19) MNC02-677F-2, (20) MNC02-65F-9-5, (21) BRS VINAGRE, (22) BRANQUINH0, (23) MNC02676F-1 e (24) MNC02-689F-2-8

e (21) BRS VINAGRE, (16) MNC03737F-5-11 e (21) BRS VINAGRE, e entre (22) BRANQUINHO e (24) MNC02-689F-2-8, com distâncias de 36,31; 37,58; 39,06; 41,13 e 41,36, respectivamente (Quadro 4). Estas maiores distâncias encontradas são indicativos de maior variabilidade entre os genótipos, o que se torna altamente desejável em programas de melhoramento. Estas combinações podem ser indicadas como progenitores para formar uma população base de um programa de melhoramento. Passos et al. (2007) afirmam que se combinados, estes genótipos podem apresentar maior eficiência na produção de híbridos superiores aos progenitores.

As combinações do genótipo (11) MNC03-725F-3 com (14) MNC03-737F-5-4 ( $\left.\mathrm{D}^{2}=9,95\right)$, assim como, do genótipo (16) MNC03737F-5-11 com (14) MNC03-737F-5-4 ( $\mathrm{D}^{2}=13$,13) são consideradas boas opções para cruzamento e obtenção de populações promissoras visando a produtividade de grãos, visto que foram os genótipos mais produtivos (Quadro 2).

Já as combinações mais similares com distâncias inferiores a $\mathrm{D}^{2}=2,00$ foram: (19) MNC02-677F-2 com (20) MNC02-65F-9-5, (11) MNC03-725F-3 com (16) MNC03737F-5-11 e (5) MNC03-737F-11 com (12) MNC03-736F-7, com distâncias de 1,59; 1,64 e 1,78, respectivamente (Quadro 4).
O método de otimização de Tocher fundamentado na matriz de dissimilaridade expressa pelas distâncias de Mahalanobis ( $\left.\mathrm{D}^{2}\right)$, possibilitou o agrupamento dos 24 genótipos avaliados em nove grupos distintos (Quadro 3).

O grupo I apresentou a maior concentração de genótipos, sendo constituído por MNC02-677F-2, MNC02-65F-9-5, BRS ITAIM, MNC02-676F-1, MNC03-737F-11, MNC02-675F-9-2 e MNC02-683F-1, correspondendo a 29,17\% dos genótipos avaliados. Os grupos II e III apresentaram o mesmo percentual de genótipos (16,67\%), sendo o grupo II constituído por MNC03-725F-3, MNC03737F-5-11, MNC02-676F-3 e MNC03-736F-7, e o grupo III, por MNC03-737F-5-9, MNC03-737F-5-10, MNC02-684F-5-6 e MNC02-675F-4-9. Os grupos IV (BRS-CAUAMÉ e MNC02-675F-4-10), $\mathrm{V}$ (BRS GUARIBA e MNC03-737F-5-4) e VI (MNC03-736F-2 e BRS VINAGRE) foram constituídos cada por $8,33 \%$ dos genótipos. Já os grupos VII (MNC02-689F-2-8), VIII (BRS-TUCUMAQUE) e IX (BRANQUINHO), foram constituídos cada por 4,17\% dos genótipos estudados. Passos et al. (2007) enfatiza que existe homogeneidade entre os genótipos dentro do grupo e heterogeneidade entre os grupos. Desta forma, combinações híbridas entre genótipos de diferentes grupos podem gerar populações promissoras. 
Diferentemente do agrupamento observado pelo método de otimização de Tocher, onde foram formados nove grupos, no dendrograma obtido pelo método UPGMA, os genótipos foram organizados em cinco grupos a partir de um corte em aproximadamente $60 \%$ da máxima distância (Figura 1).

De acordo com o dendograma, o grupo I foi constituído pelos genótipos (19) MNC02-677F-2, (20) MNC02-65F-9-5, (2) BRS ITAIM, (23) MNC02-676F-1, (4) BRS-TUCUMAQUE e (24) MNC02-689F-2-8. O grupo II foi constituído por (18) MNC03-736F-2 e (21) BRS VINAGRE. O grupo III foi composto pelo maior número de genótipos, sendo eles (11) MNC03-725F-3, (16) MNC03737F-5-11, (5) MNC03-737F-11, (12) MNC03-736F-7, (13) MNC02-676F-3, (8) MNC02-675F-9-2, (3) BRS-CAUAMÉ e (9) MNC02-675F-4-10. Os genótipos (7) MNC02-683F-1, (14) MNC03-737F-5-4 e (1) BRS GUARIBA formaram o grupo IV e o grupo $\mathrm{V}$ foi constituído pelos genótipos (15) MNC03-737F-5-9, (17) MNC03-737F-5-10, (10) MNC02-684F-5-6, (6) MNC02-675F-4-9 e (22) BRANQUINHO.

Embora tenham sido formadas diferentes composições e números de grupos pelos dois métodos de agrupamento utilizados, ambos apresentaram semelhanças nos componentes de cada grupo formado. O grupo VI formado pelo método de Tocher (Quadro 4) e o grupo II observado no dendograma a partir do método UPGMA (Figura 1), apresentaram exatamente os mesmos componentes, sendo eles os genótipos (18) MNC03-736F-2 e (21) BRS VINAGRE. Essa similaridade entre a formação dos grupos pelos dois métodos de agrupamento (Tocher e UPGMA), também foi observada por Oliveira (2015) e Gonçalves et al. (2014).

A contribuição relativa dos caracteres para a dissimilaridade genética dos 24 genótipos avaliados de acordo com o método proposto por Singh (1981) pode ser observada no Quadro 5. A produtividade de grãos obteve a maior contribuição relativa para a dissimilaridade entre os genótipos avaliados com contribuição de 24,38\% (Quadro 5). Além da produtividade, o número de dias para a maturação das vagens e o número de grãos por vagem, foram as características que mais contribuíram para a dissimilaridade entre os genótipos com 13,08 e 16,23\%, respectivamente (Quadro 5). O comprimento de vagens, e peso de cem sementes com 4,80 e $7,74 \%$ foram as características com menores contribuições relativa para a dissimilaridade. De acordo com Coelho et al. (2007), estas características com baixa percentagem de contribuição teriam pouca relevância em estudos de divergência genética. Desta forma, a utilização destas características para a seleção de progenitores em um programa de melhoramento teria pouca eficiência.

Quadro 5 - Contribuição relativa dos caracteres para dissimilaridade genética de 24 genótipos de feijão caupi de acordo com método proposto por Singh (1981)

\begin{tabular}{lc}
\hline Variáveis & Valor (\%) \\
\hline 1 Dias até à floração (DF) & 11,80 \\
2 Dias para a maturação das vagens (DMV) & 13,08 \\
3 Índice de grãos (IG) & 12,52 \\
4 Número de grãos por vem (NGV) & 16,23 \\
5 Número de vagens por planta (NVP) & \\
6 Comprimento de vagens (CVA) & 4,80 \\
7 Peso de cem grãos (PCG) & 7,74 \\
8 Produtividade de grãos (PG) & 24,38 \\
\hline
\end{tabular}

\section{CONCLUSÕES}

Os genótipos MNC03-725F-3 e MNC03737F-5-11 são promissores para cultivos na 1. a safra em condições de baixo nível tecnológico de Cerrado no Tocantins. As combinações entre os genótipos MNC03-725F-3 com MNC03-737F-5-4 e de MNC03737F-5-11 com MNC03-737F-5-4, são combinações indicadas para a obtenção de populações promissoras quanto à produtividade de grãos em condição de Cerrado no Tocantins. A produtividade de grãos e o número de grãos por vagem foram as características que mais contribuíram para a dissimilaridade dos genótipos avaliados. 


\section{REFERÊNCIAS BIBLIOGRÁFICAS}

Almeida, R.D.; Peluzio, J.M. e Afférri, F. S (2011) - Divergência genética entre cultivares de soja, sob condições de várzea irrigada, no sul do Estado Tocantins. Revista Ciência Agronômica, vol. 42, n. 1, p. 108-115. http://dx.doi.org/10.1590/S1806-66902011000100014

Benvindo, R.N.; Silva, J.A.L.; Freire Filho, F.R.; Almeida, A.L.G.; Oliveira, J.T.S. e Bezerra, A.A.C. (2010) - Avaliação de genótipos de feijão-caupi de porte semi-prostrado em cultivo de sequeiro e irrigado. Comunicata Scientiae, vol. 1, n. 1, p. 23-28.

Bertini, C.H.C.M.; Almeida, W.S.; Silva, A.P.M.; Silva, J.W.L. e Teófilo, E.M. (2010) - Análise multivariada e índice de seleção na identificação de genótipos superiores de feijão-caupi. Acta Scientiarum Agronomy, vol. 32, n. 4, p. 613-619. http://dx.doi.org/10.4025/actasciagron.v32i4.4631

Bertini, C.H.C.M.; Teófilo, E.M. e Dias, F.T.C. (2009) - Divergência genética entre acessos de feijão-caupi do banco de germoplasma da UFC. Revista Ciência Agronômica, vol. 40, n. 1, p. 99-105.

Borém, A.e Miranda, G.V. (2013) - Melhoramento de plantas. 6. ${ }^{a}$ ed. Viçosa, UFV, 523p.

Carvalho, A.F.U.; Sousa, N.M.; Farias, D.F.; Bezerra, L.C.B.R.; Silva, R.M.P.; Viana, M.P.; Gouveia, S. T.; Sampaio, S.S.; Sousa, M.B.; Lima, G.P.G.; Morais, S.M.; Barros, C.C. e Freire Filho, F.R (2012) - Nutritional ranking of 30 Brazilian genotypes of cowpeas including determination of antioxidant capacity and vitamins. Journal of Food Composition and Analysis, vol. 26, n. 1-2, p. 81-88. http://dx.doi.org/10.1016/.j.jca.2012.01.005

Coelho, C.M.M.; Coimbra, J.L.M.; Souza, C.A.; Bogo, A. e Guidolin, A.F. (2007) - Diversidade genética em acessos de feijão (Phaseolus vulgaris L.). Ciência Rural, vol. 37, n. 5, p. 1241-1247. http://dx.doi.org/10.1590/ S0103-84782007000500004

CONAB - Companhia Nacional de Abastecimento (2014) - Perspectivas para a agropecuária: safra 2014/2015. Brasília, CONAB, 155 p.

CONAB - Companhia Nacional de Abastecimento (2016) - Acompanhamento da safra brasileira: grãos, quarto levantamento, janeiro 2016. http://www.conab.gov.br/OlalaCMS/uploads/arquivos/16 0112141716 boletim graos janeiro 2016.pdf. [cit. 2016.01.29].

Cruz, C.D. (2008) - Programa genes: Diversidade Genética. 1. ed. Viçosa, Editora UFV, 278 p.

Cruz, C.D.; Ferreira, F.M. e Pessoni, L.A. (2011) - Biometria aplicada ao estudo da diversidade genética. Suprema, Visconde do Rio Branco, 620 p.

Dotto, M.A.; Afférri, F.S.; Peluzio, J.M.; Melo, A.V. e Carvalho, A.J. (2010) - Divergência genética entre cultivares comerciais de milho em baixas altitudes no Tocantins, safra 2007/2008. Revista Ciência Agronômica, vol. 41,n. 4, p. 630-637. http://dx.doi.org/10.1590/S1806-66902010000400017

EMBRAPA - Empresa Brasileira de Pesquisa Agropecuária (2013) - Sistema Brasileiro de Classificação de Solos. 3.ㄹ ed. Brasília, EMBRAPA. 353 p.

FAO - Food and Agriculture Organization of the United Nations (2016) - Production - Crops. http://faostat3. fao.org/download/Q/QC/E. [cit. 2016.01.24].

Freire Filho, F.R.; Lima, J.A.A. e Ribeiro, V.Q. (2005a) - Feijão-caupi: avanços tecnológicos. Brasília, Embrapa, 519 p.

Freire Filho, F.R.; Ribeiro, V.Q.; Barreto, P.D. e Santos, A.A. (2005b) - Melhoramento Genético. In: FreireFilho F.R, Lima J.A.A e Ribeiro V.Q (Eds.) - Feijão-caupi: avanços tecnológicos. Brasília, Embrapa, p. 28-92.

Gonçalves, D.L.; Ambrozio, V.C.; Barelli, M.A.A.; Neves, L.G.; Sobrinho, S.P.; Luz, P.B. e Silva, C.R. (2014) - Divergência genética de acessos tradicionais de feijoeiros. Bioscience Journal, vol. 30, n. 6, p. 1671-1681.

Kachare, D.P.; Chavan, J.K. e Kadam, S.S. (1988) - Nutritional quality of some improved cultivars of cowpea. Plant Foods for Human Nutrition, vol. 38, n. 2, p. 155-162. http://dx.doi.org/10.1007/BF01091720

Kloster, G.S.; Barelli, M.A.A.; Silva, C.R.; Neves, L.G.; Sobrinho, S.P. e Luz, P.B. (2011) - Análise da divergência genética através de caracteres morfológicos em cultivares de feijoeiro. Revista Brasileira de Ciência Agrárias, vol. 6, n. 3, p. 452-459. http://dx.doi.org/10.5039/agraria.v6i3a1140

Köppen, W. (1948) - Climatologia: con un estúdio de los climas de la terra. México, Fondo de Cultura Económica, $479 \mathrm{p}$.

Lopes, A.C.A.; Freire Filho, F.R.; Silva, R.B.Q.; Campos, F.L. e Rocha, M.M. (2001) - Variabilidade e correlações entre caracteres agronômicos em caupi (Vigna unguiculata). Pesquisa Agropecuária Brasileira, vol. 36, n. 3, p. 515-520. http://dx.doi.org/10.1590/S0100-204X2001000300016 
Melo, F.B.; Cardoso, M.J e Salviano, A.A.C. (2005) - Fertilidade do Solo e Adubação. In: Freire Filho FR, Lima JAA e Ribeiro VQ (Eds.) - Feijão-caupi: avanços tecnológicos. Brasília, Embrapa, p. 229-242.

Oliveira, A.P.; Sobrinho, J.T.; Nascimento, J.T. e Alves, A.U.; Abuquerque, I.C. e Bruno, G.B. (2002) - Avaliação de linhagens e cultivares de feijão-caupi, em Areia, PB. Horticultura Brasileira, vol. 20, n. 2, p. 180-182. http://dx.doi.org/10.1590/S0102-05362002000200012

Oliveira, E.; Mattar, E.P.L.; Araújo, M.L.; Jesus, J.C.S.; Nagy, A.C.G. e Santos, V.B. (2015) - Descrição de cultivares locais de feijão-caupi coletados na microrregião Cruzeiro do Sul, Acre, Brasil. Acta Amazonica, vol. 45, n. 3, p. 243-254. http://dx.doi.org/10.1590/1809-4392201404553

Oliveira, T.C. (2015) - Adaptabilidade, estabilidade e divergência genética entre cultivares de feijão comum no sul do Estado do Tocantins. Tese de Doutorado. Universidade Federal do Tocantins, Gurupi, 78 p.

Passos, A.R.; Silva, S.M.S.; Cruz, P.J.; Rocha, M.A.C.; Bahia, H.F. e Saldanha, R.B. (2007) - Divergência genética em feijão-caupi. Bragantia, vol. 66, n. 4, p. 579-586. http://dx.doi.org/10.1590/50006-87052007000400007

Santos, E.R.; Barros, H.B.; Capone, A.; Melo, A.V.; Cella, A.J.S. e Santos, W.R. (2012) - Divergência genética entre genótipos de soja com base na qualidade de sementes. Revista Brasileira de Ciências Agrárias, vol. 7, n. 2, p. 247-254. http://dx.doi.org/10.5039/agraria.v7i2a1560

Santos, E.R.; Barros, H.B.; Ferraz, E.C.; Cella, A.J.S.; Capone, A.; Santos, A.F. e Fidelis, R.R. (2011) - Divergência entre genótipos de soja, cultivados em várzea irrigada. Revista Ceres, vol. 58, n. 6, p. 755-764. http://dx.doi. org/10.1590/S0034-737X2011000600012

Santos, J.A.S.; Teodoro, P.E.; Correa, A.M.; Soares, C.M.G.S.; Ribeiro, L.P. e Abreu, H.K.A. (2014) Desempenho agronômico e divergência genética entre genótipos de feijão-caupi cultivados no ecótono Cerrado/Pantanal. Bragantia, vol. 73, n. 4, p. 377-382. http://dx.doi.org/10.1590/1678-4499.0250

Santos, M.G. (2014) - Desempenho agronômico de feijão caupi em função do espaçamento e densidade de plantas cultivado nos sistemas de várzea irrigada e Cerrado. Dissertação de Mestrado. Universidade Federal do Tocantins, Gurupi, 48 p.

Scott, A.J. e Knott, M.A. (1974) - A cluster analysis method for grouping means in the analysis of variance. Biometrics, vol. 30, n. 3, p. 507-512. http://dx.doi.org/10.2307/2529204

Silva, J.A.L. e Neves, J.A. (2011) - Componentes de produção e suas correlações em genótipos de feijão-caupi em cultivo de sequeiro e irrigado. Revista Ciência Agronômica, vol. 42, n. 3, p. 702-713. http://dx.doi.org/10.1590/ $\underline{\text { S1806-66902011000300017 }}$

Singh, D. (1981) - The relative importance of characters affecting genetic divergence. The Indian Journal of Genetics e Plant Breeding, vol. 41, n. 2, p. 237-245.

Teixeira, I.R.; Silva, G.C.; Oliveira, J.P.R.; Silva, A.G. e Pelá, A. (2010) - Desempenho agronômico e qualidade de sementes de cultivares de feijão-caupi na região do cerrado. Revista Ciência Agronômica, vol. 41, n. 2, p. 300-307. http://dx.doi.org/10.1590/S1806-66902010000200019

Vale, N.M.; Barili, L.D.; Oliveira, H.M.; Carneiro, J.E.S.; Carneiro, P.C.S. e Silva, F.L. (2015) - Escolha de genitores quanto à precocidade e produtividade de feijão tipo carioca. Pesquisa Agropecuária Brasileira, vol. 50, p. $141-148$. 